\title{
NMR Metabolomic Analysis of Fecal Water from Subjects on a Vegetarian Diet
}

\author{
Jenny Pettersson, ${ }^{a}$ Pernilla Christina Karlsson, ${ }^{b}$ Young Hae Chol, ${ }^{c}$ Robert Verpoorte,${ }^{c}$ \\ Joseph James RAFTER, ${ }^{b}$ and Lars BOHLIN $*, a$ \\ ${ }^{a}$ Division of Pharmacognosy, Department of Medicinal Chemistry, Biomedical Centre, Uppsala University; Box 574, S- \\ 75123 Uppsala, Sweden: ${ }^{b}$ Division of Medical Nutrition, Department of Biosciences and Nutrition, Karolinska Institute; \\ Novum, S-141 86 Huddinge, Sweden: and ${ }^{c}$ Division of Pharmacognosy, Section Metabolomics, Institute of Biology, Leiden \\ University; 2300 RA Leiden, The Netherlands.
}

Received December 10, 2007; accepted February 26, 2008; published online March 3, 2008

\begin{abstract}
A vegetarian diet rich in phytochemicals may prevent colon carcinogenesis by affecting biochemical processes in the colonic mucosa. Compounds passing the digestive system reaching the colon could potentially be detected in fecal water. We previously reported that intact fecal water samples from human volunteers significantly decreased prostaglandin production and COX-2 protein expression in colonic cells. The aim with the present study was to further study the composition of the fecal waters, using NMR spectroscopy and multivariate data analysis, and to trace the COX-2 inhibiting activity. Intact fecal water samples and fractions thereof were analyzed for their ability to inhibit prostaglandin $E_{2}$ production in the human colon cell line HT-29. The majority of the tested aqueous phases derived from intact fecal water showed ability to inhibit prostaglandin production in cells $(13.8 \pm 1.34 \%$ inhibition, $p=0.01)$. NMR analysis indicated the presence of significant quantities of amino acids and fatty acids. Major metabolites included; acetic acid, butanoic acid, propanoic acid, glutamic acid and alanine. Smaller amounts of glycine and fumaric acid, which are known to have anti-inflammatory and anti-tumorigenic properties, were also detected. This study describes for the first time NMR metabolomic analysis of fecal water from subjects on a vegetarian diet.
\end{abstract}

Key words metabolomic; vegetarian fecal water; cyclooxygenase-2 inhibitor; nuclear magnetic resonance; colon cancer

Plant based food contains a multiplicity of bioactive phytochemicals. These compounds are believed to contribute to the cancer protective effect of a diet high in fruit and vegetables. ${ }^{1,2}$ One group of phytochemicals is the cyclooxygenase2 (COX-2) inhibitors, which potentially can act as preventive agents against colon cancer. Such compounds and their derivatives may pass through the digestive system and reach the colon where they exert chemopreventive effects.

The water fraction of feces (fecal water) is believed to be in direct contact with the colonocytes, and its composition appears to be important for a healthy environment in the colon. ${ }^{3)}$ It is believed that the fecal water composition roughly reflects the food intake and that it contains a mixture of compounds that may prevent and promote cancer development. A favorable change in the composition of fecal water would consequently decrease the risk of developing colon cancer. ${ }^{4)}$ Fecal water is nowadays a common tool used in human intervention studies. It is used to test cellular responses in vitro in cell systems. ${ }^{5-8)}$ Such studies have shown that fecal water can modulate several cellular parameters such as genotoxicity, proliferation and apoptosis, all of which are relevant for tumorigenesis. ${ }^{9-11)}$ Other human intervention studies have indicated that it is possible to alter the $\mathrm{pH}$ and the composition of bile acids in fecal water with a change in the diet. ${ }^{3,12)}$ Another parameter that can be modulated by fecal water is the colonic COX-2 enzyme. We have recently shown that fecal waters from human volunteers inhibit COX2 protein expression and prostaglandin $\mathrm{E}_{2}\left(\mathrm{PGE}_{2}\right)$ production in colonic cells. ${ }^{13)}$

COX-2 is the inducible form of two isoforms of cyclooxygenases, and it catalyzes the production of prostaglandins. This enzyme is not normally expressed in the colon, but it can be induced by growth factors, cytokines, tumor necrosis factor and lipopolysaccharides in situations of stress. ${ }^{14-16)}$ An over expression of COX-2 protein and an increased production of prostaglandins have been reported in patients with colon cancer, ${ }^{17-19)}$ and inhibition of the COX-2 enzyme has been a drug target over the past fifteen years. Today, there are several specific COX-2 inhibitors available on the market, but some of these synthetic drugs were recently reported to have severe side effects on the cardiovascular system. ${ }^{20,21)}$

To characterize a complex mixture of metabolites such as fecal water, a comprehensive metabolite profiling method is required. Metabolomic profiling of complex extracts is not an easy task to perform since they usually display a wide range of structural diversity. Of the possible analytical methods used in metabolomics, NMR provides a rapid, reproducible method well suited for identification of many metabolites and it has several advantages compared to other methods. It is not only the high information content of the resulting spectra for chemical structures but also the convenience in practical aspects such as high reproducibility of NMR chemical shifts, the easy comparison of relative amount of metabolites and less requirements of pre-separation steps needed before analysis. In addition, a broad range of metabolites could be detected at the same time, when the concentration is above a certain level. The range of compounds that can be analyzed is not limited by their volatility, the presence of a chromophore, or the polarity. To handle and analyze the huge amounts of data generated by NMR-based metabolomics multivariate and pattern recognition techniques are important tools. Principal component analysis (PCA) is an unsupervised clustering method requiring no knowledge of the data set and acts to reduce the dimensionality of multivariate data while preserving most of the variance within it. ${ }^{22)}$ 
NMR metabolomic methods have previously been used both for studies of plant material and of human biofluids. ${ }^{23-26)}$ Urine, blood plasma, sweat, aqueous humour, cerebrospinal fluid, amniotic fluid, seminal plasma, bile and synovial fluid are examples of biofluids that have been investigated by use of NMR. ${ }^{26}$ ) By combining NMR and multivariate statistic methods, it is possible to identify biomarkers of diseases and toxicity. ${ }^{27,28)} \mathrm{A}$ metabonomic study of fecal extracts from patients with inflammatory bowel disease was recently performed, suggesting that metabonomics has a potential to be used for noninvasive diagnosis of gastrointestinal disease. ${ }^{29)}$ In a previous study we showed that fecal waters from human healthy volunteers on a vegetarian diet possessed COX-2 inhibitory activity in colonic cells. ${ }^{13)}$ In the present study a NMR metabolomic approach has been used to study the chemical profile of the contents of the intact fecal waters and the derived water phases.

\section{MATERIALS AND METHODS}

Study Design Twenty-four hour stool samples were collected from 20 vegetarians and frozen below $-20^{\circ} \mathrm{C}$, as described elsewhere. ${ }^{13)}$ Subjects with a regular intake of nonsteroidal anti-inflammatory drugs (NSAIDs) or other anti-inflammatory drugs were excluded from the study. The study protocol was approved by the Medical Ethical Committee of Huddinge University Hospital in Stockholm, Sweden.

Materials Arachidonic acid, aspirin, prostaglandin $\mathrm{E}_{2}$, Anti-prostaglandin $\mathrm{E}_{2}$, TNF- $\alpha$, 4-hydroxy-3-methoxycinnamic acid (ferulic acid), 3-phenylpropionic acid, 3-hydroxyphenylacetic acid, 3,4-dihydroxyphenylacetic acid, and 3-(4-hydroxy-phenyl)-propionic acid were obtained from Sigma-Aldrich (Stockholm, Sweden). NS-398 ([ $N$-[2-(cyclohexyloxy)-4-nitrophenyl]methanesulfonamide]) was from Cayman Chemical Co. (Ann Arbor, MI, U.S.A.). DMEM (Dulbecco's Modified Eagle's Medium-high glucose) and Trypsin-EDTA were purchased from Invitrogen (Taastrup, Denmark). $\left[{ }^{3} \mathrm{H}\right]$ Prostaglandin $\mathrm{E}_{2}$ was obtained from Amersham Biosciences (Uppsala, Sweden). Stock solutions of arachidonic acid, aspirin and prostaglandin respectively were made by dissolving the compounds in EtOH.

Fecal Water Preparation Fecal water from 20 vegetarians was prepared according to a general procedure. Each fecal sample was homogenized for $2 \mathrm{~min}$ and fecal water was prepared by centrifugation of $25 \mathrm{~g}$ feces for $2 \mathrm{~h}$ at $30000 \times \boldsymbol{g}$ at $10{ }^{\circ} \mathrm{C}$. The supernatant was decanted and stored at $-20^{\circ} \mathrm{C}$ until analysis. All fecal water extracts were sterile filtered (Millipore, $0.8 / 0.2 \mu \mathrm{m}$ ) and stored at $-20^{\circ} \mathrm{C}$ until analysis.

Fractionation of Fecal Water Samples In order to characterize the COX-2 inhibitory activity of the fecal waters, these were fractionated into an aqueous and a lipid phase by solid phase extraction (SPE) on a C18 column. Fecal water samples were fractionated as follows: fecal water $(0.5 \mathrm{ml})$ was diluted in water $(1: 10)$, and applied on a pre-conditioned SPE column (Isolute ${ }^{\circledR}$ C18 (EC) $500 \mathrm{mg} / 10 \mathrm{ml}$, Sorbent, Göteborg, Sweden). The cartridge was then eluted with water $(10 \mathrm{ml})$, and acetonitrile $(10 \mathrm{ml}$, HPLC-grade, Merck, Darmstadt, Germany), to obtain two fractions. The aqueous phase was freeze-dried and the acetonitrile fraction was evaporated to dryness in $\mathrm{N}_{2}$ gas. The fractions were resuspended in $0.5 \mathrm{ml} \mathrm{H}_{2} \mathrm{O}$ (aqueous phase), and $0.5 \mathrm{ml} \mathrm{PBS}$ (lipid phase), respectively. The COX-2 inhibitory effects of the fractions were investigated. All fecal waters were tested for cytotoxicity in the AlamarBlue ${ }^{\mathrm{TM}}$ assay to ensure that potential COX-2 inhibitory effects were not due to cell death. Consequently samples with cytotoxic effects (i.e. samples reducing the cell viability with more than $10 \%$ ) were excluded and also debarred from further fractionation and analysis. Due to variations in fecal water volume from individual subjects the amount of some samples was limited. Hence, only part of the samples could be further fractionated and analyzed.

The aqueous phase of 6 fecal water samples was further divided into 5 new fractions using Sephadex gel chromatography. The freeze-dried residues of the water fractions from the solid phase extraction (SPE) column chromatography were applied to a Sephadex LH-20 gel (Sephadex ${ }^{\mathrm{TM}}$ LH-20, Amersham Pharmacia, Uppsala, Sweden) swelled in methanol. The samples were eluted by a step gradient of increasing polarity. Fifty milliliters of eluent was applied and collected in each fraction; pure $\mathrm{MeOH}, \mathrm{MeOH}: \mathrm{H}_{2} \mathrm{O} 3: 1$, $\mathrm{MeOH}: \mathrm{H}_{2} \mathrm{O} 1: 1, \mathrm{MeOH}: \mathrm{H}_{2} \mathrm{O} 1: 3$. Finally the gel was washed with $100 \mathrm{ml} \mathrm{H}_{2} \mathrm{O}$. The methanol fractions were evaporated in a rotation evaporator under vacuum and the remaining water was removed by freeze drying. The dried residue from each fraction was re-dissolved in $0.5 \mathrm{ml} \mathrm{PBS}$ and evaluated for COX-2 inhibitory activity.

Cell Culture The human colon adenocarcinoma cell line HT-29 (American Type Culture Collection, Rockville, MD, U.S.A.), was cultured in monolayer in DMEM (Dulbecco's modified Eagle medium supplemented with $10 \%$ fetal bovine serum, $2 \mathrm{mmol} / 1$ L-glutamine, and $1 \%$ penicillin/streptomycin) at $37^{\circ} \mathrm{C}$ and $5 \% \mathrm{CO}_{2}$. All experiments were carried out using $0.1 \%$ DMEM $(0.1 \%$ FBS $)$. Pure compounds were dissolved in ethanol or DMSO and diluted in $0.1 \%$ DMEM (with the final concentration in the cell cultures being maximum $0.25 \%$ of ethanol or DMSO).

PGE, Production in HT-29 Cells HT-29 cells were seeded out into a 12 well microtiter plate at a concentration of $3.30 \times 10^{5}$ cells/well. On day $2,100 \mu \mathrm{mol} / 1$ aspirin was added to the media to prevent activation of COX-1. At day 3, the cells were incubated with TNF- $\alpha(50 \mu \mathrm{g} / 1)$ and test component (lipid or aqueous fraction of fecal water or pure phenolic compounds) for $5 \mathrm{~h}$. All fecal water fractions were diluted 1:20 with DMEM. Pure phenolic compounds were tested in concentrations $250-500 \mu \mathrm{mol} / 1$. Untreated cells were included in each experiment. At the end of the incubation, the test solution was removed and replaced with $100 \mu \mathrm{mol} / 1$ arachidonic acid. After $1 \mathrm{~h}$ incubation the medium was transferred to Eppendorf tubes and stored at $-80{ }^{\circ} \mathrm{C}$ until analysis. The concentration of released $\mathrm{PGE}_{2}$ was quantified using RIA, according to the protocol supplied by Sigma Chemical Company, using anti-PGE 2 (Sigma) and $\left[{ }^{3} \mathrm{H}\right]$-labelled $\mathrm{PGE}_{2}$ (Amersham Pharmacia Biotech).

Quantification of $\mathbf{P G E}_{2}$ in Fecal Water The concentration of $\mathrm{PGE}_{2}$ in intact fecal water was quantified using RIA, according to the protocol supplied by Sigma Chemical Company as above.

Statistical Analysis All data were analyzed with the statistical software Statistica version 7.01 (StatSoft, Tulsa, U.S.A.). Individual results for the fecal water fractions were compared with TNF- $\alpha$ induced cells with Kruskal Wallis test (unequal variance). Results are presented as mean \pm S.E.M. 
$p<0.05$ was regarded as significant.

NMR and PCA Ten intact fecal waters and 6 aqueous fractions were subjected to NMR analysis. As mentioned previously, the number of samples analyzed was limited due to variation in fecal water volume from different subjects. Prior to analysis, $800 \mu \mathrm{l} \mathrm{KH}_{2} \mathrm{PO}_{4}$ buffer $(90 \mathrm{~mm}$, $\mathrm{pH}$ 6) containing $0.08 \%$ TSP (trimethyl silyl propionic acid sodium salt, w/v) was added to each sample (200 $\mu \mathrm{l}$ of intact fecal water or the aqueous phase of fecal water). Parameters for NMR spectroscopy were previously described by Choi and co-workers. ${ }^{23,24)}$ In brief, ${ }^{1} \mathrm{H}-\mathrm{NMR}$ and $J$ resolved spectra were recorded at $25^{\circ} \mathrm{C}$ on a $400 \mathrm{MHz}$ Bruker AV-400 spectrometer operating at a proton NMR frequency of 400.13 $\mathrm{MHz} . \mathrm{D}_{2} \mathrm{O}$ was used as the internal lock. Each ${ }^{1} \mathrm{H}-\mathrm{NMR}$ spectrum consisted of 128 scans requiring $10 \mathrm{~min}$ acquisition time with the following parameters: $0.25 \mathrm{~Hz} /$ point, pulse width $(\mathrm{PW})=90^{\circ}(6.6 \mu \mathrm{s})$, and relaxation delay $(\mathrm{RD})=5.0 \mathrm{~s}$. FIDs were Fourier transformed with $\mathrm{LB}=0.3 \mathrm{~Hz}$ and the spectra were zero filled to $32 \mathrm{~K}$ points. The resulting spectra were manually phased and baseline corrected, and calibrated to TSP at $0.0 \mathrm{ppm}$, using XWIN NMR (version 3.5, Bruker). 2-D $J$-resolved ${ }^{1} \mathrm{H}$-NMR spectra were acquired using 8 scans per 32 increments that were collected into $16 \mathrm{~K}$ data points, using spectral widths of $5208 \mathrm{~Hz}$ in F2 (chemical shift axis) and $50 \mathrm{~Hz}$ in $\mathrm{F} 1$ (spin-spin coupling constant axis). A $1.0 \mathrm{~s}$ relaxation delay was employed, giving a total acquisition time of $14.52 \mathrm{~min}$. Datasets were zero-filled to 512 points in F1 and both dimensions were multiplied by sine-bell functions $(\mathrm{SSB}=0)$ prior to double complex FT. $J$-resolved spectra were tilted by $45^{\circ}$, symmetrized about F1, and then calibrated, using XWIN NMR (version 3.5, Bruker). Data were exported as the $1 \mathrm{D}$ projection (F2 axis) of the $2 \mathrm{D} J$-resolved spectra. The spectral interpretation was confirmed by correlation spectroscopy (COSY), heteronuclear multiple bond coherence (HMBC), heteronuclear multiple quantum coherence (HMQC). ${ }^{1} \mathrm{H}-{ }^{1} \mathrm{H}-\mathrm{COSY}, \mathrm{HSQC}$, and HMBC were measured on a $600 \mathrm{MHz}$ Bruker DMX-600 spectrometer operating at a proton NMR frequency of $600.13 \mathrm{MHz}$. The COSY spectra were acquired with $1.0 \mathrm{~s}$ relaxation delay, $6361 \mathrm{~Hz}$ spectral width in both dimensions. Window function for COSY spectra was sine-bell $(\mathrm{SSB}=0)$. The HSQC spectra were obtained with $1.0 \mathrm{~s}$ relaxation delay, $6361 \mathrm{~Hz}$ spectral width in F2 and $27164 \mathrm{~Hz}$ in $\mathrm{F} 1$. Qsine ( $\mathrm{SSB}=2.0$ ) was used for the window function of HSQC. The HMBC spectra were recorded with the same parameters as the HSQC spectrum except for $30183 \mathrm{~Hz}$ of spectral width in F2. The optimized coupling constants for HSQC and HMBC were $145 \mathrm{~Hz}$ and $8 \mathrm{~Hz}$, respectively.

The ${ }^{1} \mathrm{H}-\mathrm{NMR}$ and the $J$-resolved projection spectra were automatically reduced to ASCII files using AMIX (v. 3.7, Bruker Biospin). Spectral intensities were scaled to TSP and reduced to integrated regions of equal width $(0.04 \mathrm{ppm})$ corresponding to the region of $\delta-0.40-\delta 10.00$. The region of $\delta 4.7-\delta 5.0$ was excluded from the analysis because of the residual signal of water. The region of citric acid, malic acid, and succinic acid in $\delta 2.8-\delta 2.5$ was bucketed by $0.1 \mathrm{ppm}$ in order to avoid problems due to the dependence of the chemical shifts on the concentration of these compounds.

The spectral interpretation was based on characteristic ${ }^{1} \mathrm{H}-$ NMR signals and was confirmed by several kinds of 2-D NMR methods, such as COSY, HMBC and HMQC. Among the 2-D-spectra, the $J$-resolved NMR technique was useful in many cases by improving the resolution and facilitating identification of the metabolites. Principle component analyses (PCA) were performed with the SIMCA-P software (v. 11.0, Umetrics, Umeå, Sweden). Pareto scaling method was used, which gives each variable a variance numerically equal to its initial standard deviation.

\section{RESULTS}

Fractionation of Fecal Waters with COX-2 Inhibitory Activity The majority of the 16 tested aqueous phases of fecal water significantly inhibited the $\mathrm{PGE}_{2}$ production in TNF- $\alpha$ stimulated HT-29 cells (Fig. 1). Three samples (16, 19, 20) showed minor effects. None of the 19 tested lipid fractions of fecal water had an effect on the $\mathrm{PGE}_{2}$ production (Fig. 1). To exclude effects due to toxicity, only non-cytotoxic fecal waters were included in the analysis (samples that did not reduce cell viability more than $10 \%$ ). When the aqueous phase of fecal water was further fractionated by Sephadex column chromatography, the COX-2 inhibiting activity was lost. This result could be due to a synergistic activity of several components. The synergy hypothesis could not be tested due to too small available amount of material.

PGE $_{2}$ Levels in Fecal Water In order to test if the concentration of prostaglandins in fecal water was linked to the COX-2 inhibitory activity of the fecal waters, we analyzed the concentration of prostaglandin E2 in intact fecal waters. The concentration in fecal water ranged from 1900$4200 \mathrm{pg} / \mu \mathrm{l}$ fecal water (Fig. 2). No correlation between $\mathrm{PGE}_{2}$ levels in fecal water and inhibitory activity of the intact phase of fecal water could be detected $(r=0.34)$.

Chemical Characterization of Fecal Water Samples by NMR Metabolomic Analysis Visual inspection of the ${ }^{1} \mathrm{H}$ NMR-spectra of ten fecal water samples resulted in the identification of several components (Table 1). The relative amounts of the compounds identified in the individual fecal waters are presented in Table 1. Similar metabolomic patterns were observed for all fecal waters tested. The major differences were in the regions of phenolics, amino acids and short chain fatty acids (Tables 1,2 ). The relative intensities of saturated and unsaturated fatty acids, and phenolic compounds in the fecal waters were compared (Table 2). The complexity of the spectra made complete interpretation impossible. The numerous NMR signals of the fecal waters were reduced by PCA to two principal components (PC1, PC2). The first component explains $39.8 \%$ of the variation between the samples and the second component $18.4 \%$ (Fig. 3 ). The amount of the identified compounds is highly variable within the ten individual vegetarian fecal water samples.

Inhibition of COX-2 by Fecal Water Components Various combinations of phenolic compounds, previously reported to be found in fecal water, ${ }^{13)}$ were investigated for their ability to inhibit $\mathrm{PGE}_{2}$ production in HT-29 cells. The five phenolic compounds; 4-hydroxy-3-methoxycinnamic acid (ferulic acid), 3-phenyl-propionic acid, 3-hydroxyphenylacetic acid, 3,4-dihydroxyphenylacetic acid, and 3-(4-hydroxy-phenyl)-propionic acid were tested in different combinations. The five phenolics were tested all together, four and four, three and three and two and two. None of the single phenolic derivatives or any combination thereof had effect on 


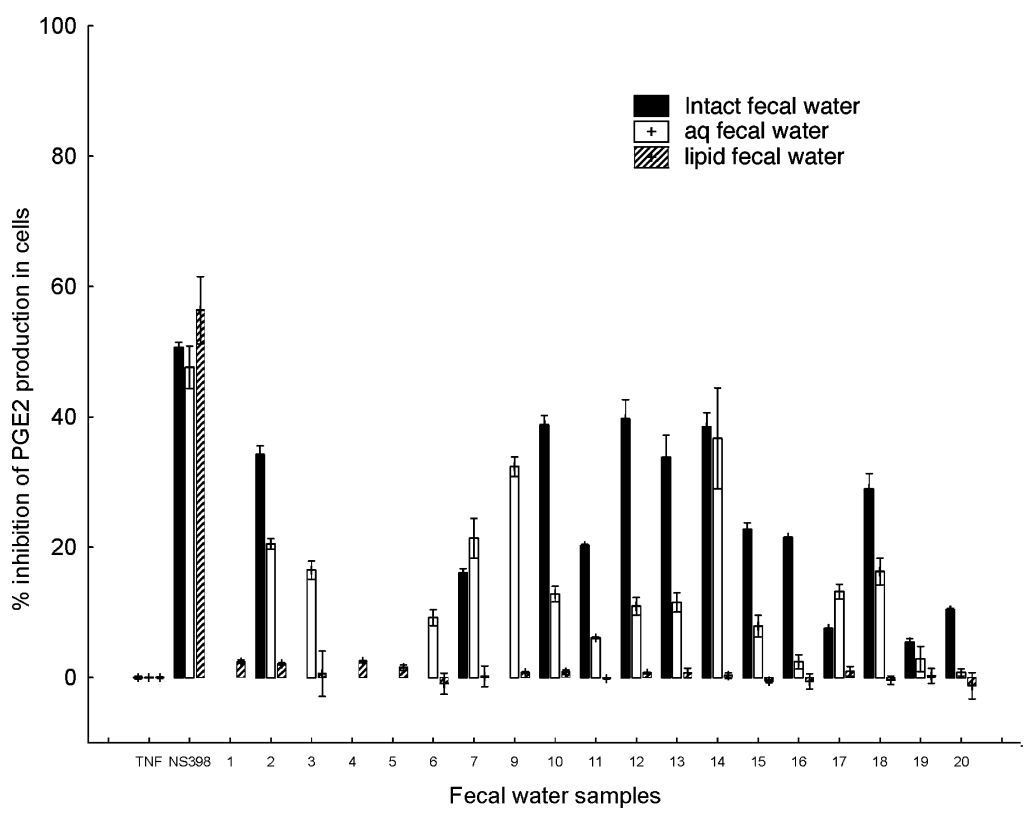

Fig. 1. The Aqueous Phase of Human Fecal Waters Decreased PGE $_{2}$ Production in HT-29 Cells

Results are presented as relative inhibition of $\mathrm{PGE}_{2}$ production in cells (values are normalized for an easy comparison between different experiments). HT-29 cells stimulated with TNF- $\alpha(50 \mu \mathrm{g} / 1)$ for $5 \mathrm{~h}$ (TNF); HT-29 cells simultaneously treated with TNF- $\alpha(50 \mu \mathrm{g} / 1)$ and NS-3298 (25 $\mu$ mol/1) (NS398); HT-29 cells simultaneously treated with TNF- $\alpha$ $(50 \mu \mathrm{g} / \mathrm{l})$ and intact fecal water, aqueous phase or lipid phase of fecal water (diluted $1: 20)(1-7,9-20)$. The results for intact fecal water are published elsewhere, ${ }^{13)}$ but are shown for comparative purposes. All aqueous phases of fecal water, apart from samples 16, 19, 20 significantly inhibited $\mathrm{PGE}_{2}$ production compared to TNF- $\alpha$ treated control cells (Kruskal-Wallis test, $p<0.05$ ). The lipid phase of fecal water had no effect on $\mathrm{PGE}_{2}$ production in cells. Diagram bars represent mean \pm S.E.M.

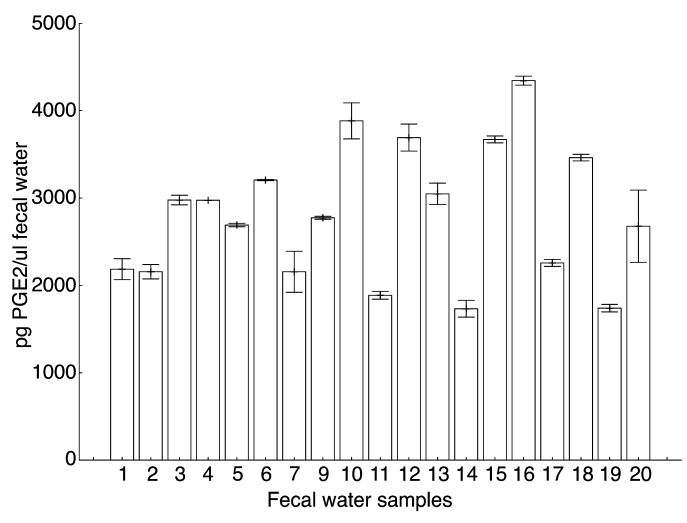

Fig. 2. The Concentration of $\mathrm{PGE}_{2}$ in Individual Fecal Waters Ranged from 1900 to $4200 \mathrm{pg} / \mu 1$ Fecal Water

No correlation between $\mathrm{PGE}_{2}$ levels in fecal water and inhibitory activity of the in tact phase of fecal water could be detected. Diagram bars represent mean \pm S.D.

$\mathrm{PGE}_{2}$ production in cells (data not shown).

\section{DISCUSSION}

Despite the fact that many human studies have used fecal water as a tool to test effects of dietary interventions, ${ }^{30,31)}$ little is known about the actual composition of fecal water. More is known about the effect of fecal water on cells, and how these effects can be modulated by the diet. $^{10,31,32)} \mathrm{We}$ have previously shown that intact human fecal water has the ability to inhibit COX-2 protein expression and $\mathrm{PGE}_{2}$ production in cells. ${ }^{13)}$ Many compounds of dietary origin could possibly be responsible for this effect. $\beta$-Carotenes, flavonoids and specific fatty acids are dietary components known to act as COX-2 inhibitors in vitro and in animal models. ${ }^{33-35)}$ These compounds and/or metabolites thereof are likely to show up in the water phase of feces. It is believed that the local effect in the gastrointestinal tract of such compounds is of more importance than their serum level. ${ }^{36}$ ) Thus, we considered it of interest to look for natural COX-2 inhibitors in human fecal water. Compounds previously reported to be present in fecal water include; neutral steroids, long and short chain fatty acids, and bile acids. ${ }^{5,37,38)}$ More recently, phenolic compounds were identified in fecal water. ${ }^{13,39)}$ Some of the major phenolic derivatives identified inhibited COX-2 protein expression but did not affect $\mathrm{PGE}_{2}$ production in HT-29 cells. ${ }^{13)}$

In this study we further characterized the content of fecal water by separation and NMR spectroscopic analysis of a number of samples from vegetarian individuals. The aim was to get a general view of the colonic contents and to identify the components therein. NMR analysis has several advantages for analysis of a complex mixture, such as fecal water; it is possible to compare the content profile from individual samples, compounds that are impossible to detect by ultraviolet spectroscopy (UV) can be detected by use of NMR and the spectral data can be analyzed by multivariate data analysis. NMR metabonomic studies of fecal extracts from humans with inflammatory bowel disease and healthy individuals have previously been performed, ${ }^{29)}$ but as far as we know metabolomic analysis of fecal water from vegetarians is a new approach. In our study the NMR metabolomic profiles from the individual fecal water samples were similar. The main differences were quantitative variation between spectral peaks. The variation in metabolic profile could depend on the intake of fruit and vegetables or variation in gastrointestinal microflora. The colonic microflora is of importance in the metabolism of dietary phenolic compounds. ${ }^{40-43)}$

The ten intact fecal waters analyzed contained a wide range of short chain fatty acids, amino acids, carbohydrates 


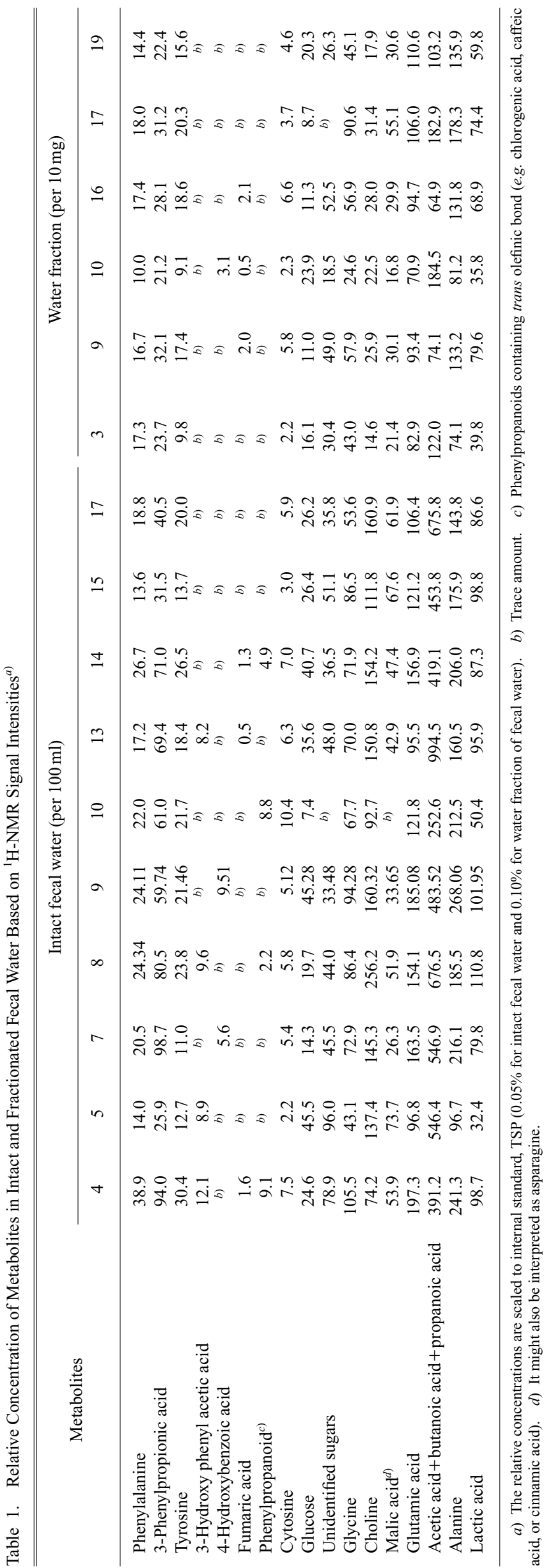

Table 2. Relative NMR Intensity of Saturated and Unsaturated Fatty Acids, and Phenolic Compounds in Intact Fecal Water ${ }^{a}$

\begin{tabular}{cccc}
\hline \hline Sample No. & $\begin{array}{c}\text { Saturated FA } \\
(\delta 0.9)\end{array}$ & $\begin{array}{c}\text { Unsaturated FA } \\
(\delta 0.96)\end{array}$ & $\begin{array}{c}\text { Phenolics } \\
(\delta 6.0-\delta 8.0)\end{array}$ \\
\hline 4 & 151.3 & 6.7 & 1.2 \\
5 & 108.5 & 11.7 & 3.6 \\
7 & 168.9 & 11.8 & 4.6 \\
8 & 169.8 & 3.6 & 1.3 \\
9 & 158.1 & 4.6 & 2.7 \\
10 & 210.5 & 8.7 & 5.1 \\
13 & 146.2 & 11.4 & 6.1 \\
14 & 231.4 & 3.4 & 5.8 \\
15 & 205.3 & 19.4 & 2.5 \\
17 & 94.8 & 8.7 & 3.5 \\
\hline
\end{tabular}

a) Relative NMR intensity was based on internal standards (TSP, $0.08 \%, \mathrm{v} / \mathrm{w}$ ).

and phenolics. The major metabolites in all samples were; acetic acid, butanoic acid, propanoic acid, alanine and lactic acid (Table 1). Small amounts of glycine were also detected. Comparison of NMR spectra from different fecal waters showed that the major differences were in the regions of phenolics, amino acids and short chain fatty acids (Tables 1,2). A number of fatty acids occurring in the human diet, including $\alpha$-linolenic acid, linoleic acid, docosahexaenoic acid and eicosapentaenoic acid as well as ursolic acid have previously been shown to inhibit COX-2 catalysed prostaglandin biosynthesis and markedly inhibited COX-2 in mice and in in vitro experiments. ${ }^{33,44}{ }^{46)}$ In line with this, olive oil and fish oil, which are complex mixtures of fatty acids have been reported to inhibit COX-2 protein expression. ${ }^{47}$ Short chain fatty acids are known to modulate different molecular mechanisms of importance in colon cancer cells ${ }^{48,49)}$ and have been extensively studied for their ability to affect colonic function. ${ }^{50)}$ Butyrate has been shown to suppress COX-2 activity ${ }^{51)}$ to increase COX-2 protein expression and to inhibit growth in HT-29 colon cancer cells. ${ }^{52)}$ The amino acids lysine and proline in combination with ascorbic acid and green tea extract have antitumour properties in animal models. ${ }^{53)}$ Glycine, which is an anti-inflammatory agent has similar properties. ${ }^{54,55)}$ Additionally, the NMR analysis confirmed the presence of phenolics that were previously identified by mass spectrometric analysis. ${ }^{13)}$ Both in the intact fecal water and in the aqueous phase, the phenolic compounds phenylalanine, 3-phenylpropionic acid, hydroxyl phenyl acetic acid and 3-hydroxy phenyl acetic acid were identified. The quantitative amount of phenolics was not measured in the NMR analysis and can therefore not be directly compared with the amounts previously detected by mass spectrometry. Another compound not previously identified in fecal water is fumaric acid (Table 1). Fumaric acid is part of the citric acid cycle and is used to treat psoriasis and it also has antitumorigenic properties in animal models. ${ }^{56-58)}$

By PCA we attempted to correlate the fecal water composition to COX-2 inhibitory activity of the individual samples. From the analysis we concluded that phenylalanine, short chain fatty acids, alanine, glutamic acid, glycine and lactate were present in higher amounts in samples 5, 7, 9, 10, 13, 14, 15 and 17 whereas the amounts of tyrosine, cytosine and glucose were higher in samples 4 and 8 (Fig. 3). The variation in COX-2 inhibitory activity of the fecal waters (Table 3 ) may be related to these differences. However, a more extensive 


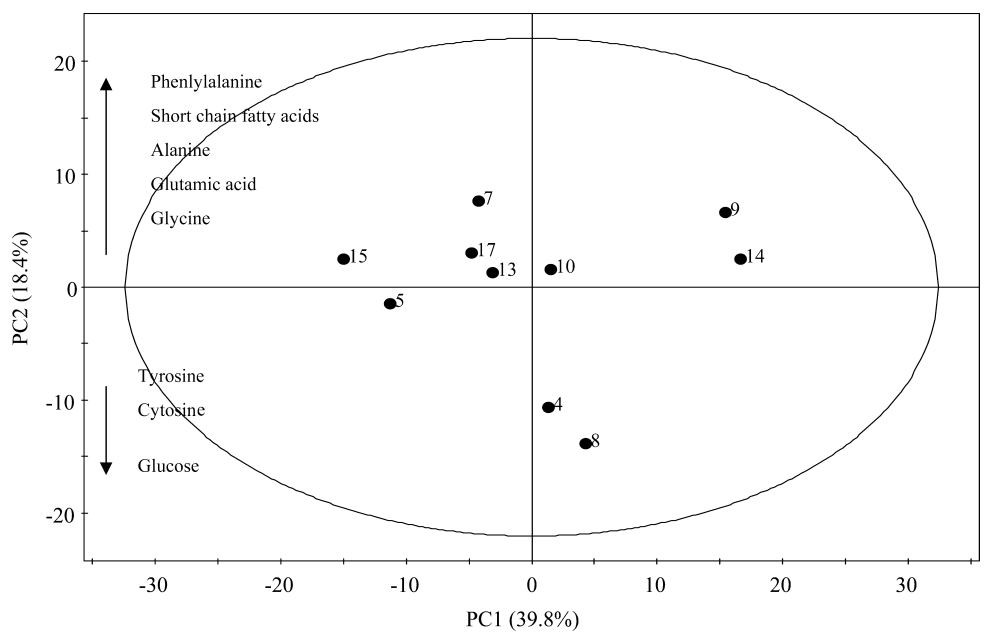

Fig. 3. Score Plot from Principal Component Analysis of Intact Fecal Water Samples

The NMR signals were reduced to two principal components (PC1, PC2). PC1 explains $39.8 \%$ of the variation and PC2 $18.4 \%$. Phenylalanine, short chain fatty acids, alanine, glutamic acid, glycine and lactate were present in higher amounts in samples 5, 7, 9, 10,13,14, 15 and 17 whereas the amount of tyrosine, cytosine and glucose was higher in samples 4 and 8. Samples 5, 7, 10, 13, 14, 15 and 17 all inhibited COX-2 protein expression in HT-29 colon cancer cells (34-58\% inhibition) in our previous study, as presented in Table 3.

Table 3. Summary of COX-2 Vegetarian Study

\begin{tabular}{|c|c|c|c|}
\hline ID & Diet & $\begin{array}{c}\% \mathrm{PGE}_{2} \text { inhibition } \\
\text { in cells } \\
\text { (intact } \mathrm{fw})\end{array}$ & $\begin{array}{l}\% \text { inhibition of } \\
\text { COX-2 protein } \\
\text { Western blot } \\
\text { (intact fw) }\end{array}$ \\
\hline 4 & Lacto-ovo & Detached cells $^{a}$ ) & Detached cells $^{a}$ \\
\hline 5 & Vegan & Detached cells $\left.{ }^{a}\right)$ & $42 \pm 0.3$ \\
\hline 7 & Lacto-ovo & $16 \pm 0.6$ & $39 \pm 1.6$ \\
\hline 8 & Vegan & Detached cells ${ }^{a)}$ & Detached cells $\left.^{a}\right)$ \\
\hline 9 & Vegan & Detached cells $\left.{ }^{a}\right)$ & Detached cells $\left.^{a}\right)$ \\
\hline 10 & Vegan & $39 \pm 1.5$ & $57 \pm 0.1$ \\
\hline 13 & Vegan & $34 \pm 3.4$ & $58 \pm 4.1$ \\
\hline 14 & Lacto-ovo & $38 \pm 2.2$ & $54 \pm 9.5$ \\
\hline 15 & Semi (fish) & $23 \pm 1.0$ & $34 \pm 1.2$ \\
\hline 17 & Vegan & $8 \pm 0.1$ & $37 \pm 6.7$ \\
\hline
\end{tabular}

Fecal water samples were evaluated for their COX-2 inhibiting properties. Results are presented as mean \pm S.E.M., $n=3$. a) These samples were toxic to the cells and gave rise to detachment of cells from the culture plate surface.

study, including a larger number of samples, is needed to confirm these findings. The major part of the COX-2 inhibitory activity of fecal water was present in the aqueous fraction after SPE, indicating that the active components are polar in nature. The COX-2 inhibitory ability of fecal water cannot be explained by the five tested phenolic compounds alone or in combination, but other phenolics may be contributing to the effect.

Differences in diet can affect the metabolites identified in body fluids. ${ }^{59-62)}$ Salicyluric and salicylic acids are examples of compounds that are excreted in urine in higher concentrations in vegetarians than in omnivores. ${ }^{59)}$ Several of the compounds we have identified in fecal water could be of plant origin. Amino acids such as phenylalanine, tyrosine, alanine and glycine, are common in plant material. Fumaric acid, phenylpropanoid, malic acid, glutamic acid and sugars could also be of plant origin. Another possibility is that compounds found in fecal water are excreted from microorganisms in the colon. Microorganisms can influence the composition of the colonic contents in two ways. They have the ability to metab- olize ingested compounds and may also contribute by de novo production of molecules in the colon. Short chain fatty acids (i.e. acetate, butyrate, propanoate and lactate) are known to be fermentation products of carbohydrates and amino acids formed by intestinal bacteria. ${ }^{50)}$ Accordingly, the COX-2 inhibitors can possibly originate from the diet or be products or metabolites of the colonic microflora.

NMR analysis of fecal water provides a non-invasive method for analysis of the large bowel status in human subjects. Originally, we choose to initiate a screening study with a group of vegetarians because a diet rich in fruit and vegetables would be more likely to result in high luminal levels of protective agents. In future studies it would be favorable to increase the number of subjects, to monitor the vegetarian diet in detail and to include a control group of omnivores. By comparing NMR metabolomic fingerprints from vegetarians and omnivores, and by testing fecal waters from both groups for COX-2 inhibition in vitro, it would be easier to draw conclusions about active components present in fecal water. With more sample material it would also be possible to pool derived fractions to test synergistic activity. Furthermore, comparing fecal water profiles from groups of different health status could be a promising strategy in the search for colon cancer biomarkers.

In conclusion we characterized the contents of a number of human fecal waters by use of NMR spectroscopy. We found that NMR is a feasible method for studies of fecal water composition although the spectra are very complex. We identified a number of components in human fecal water with reported biological activities. We believe that metabolomic studies of human fecal samples from subjects with different health status, diet and genetic characteristics (metabolomic fingerprinting) can provide useful information about the importance of the colonic contents in healthy and diseased individuals. An interesting target is the identification of the COX-2 inhibitors in fecal water, which originate from diet, and to identify the dietary source of these compounds in order to design new dietary recommendations to decrease colon cancer risk. 
Acknowledgements This work was supported by grants from Agricultural Sciences and Spatial Planning (FORMAS), the Swedish Cancer Society, and Stiftelsen Ruth och Richard Julins Fond. Our research is also partly supported by ECNIS (Environmental Cancer Risk, Nutrition and Individual Susceptibility), a network of excellence operating within the European Union 6th Framework Program, Priority 5: "Food Quality and Safety" (Contract No. 513943). Special thanks are due to Uddeholms Aktiebolags stipendiefond for the grant to Jenny Pettersson. The authors want to thank Dr. Ulrika Huss and Dr. Ulf Göransson for helpful discussion and assistance in the project.

\section{REFERENCES}

1) Rafter J., Br. J. Nutr., 88 (Suppl.), S219-S224 (2002).

2) Surh Y.-J., Nat. Rev. Cancer, 3, 768 -780 (2003)

3) Rafter J. J., Child P., Anderson A. M., Alder R., Eng V., Bruce W. R., Am. J. Clin. Nutr., 45, 559-563 (1987).

4) Bruce W. R., Giacca A., Medline A., Cancer Epidemiol. Biomarkers Prev., 9, 1271-1279 (2000).

5) Dolara P., Caderni G., Salvadori M., Morozzi G., Fabiani R., Cresci A., Orpianesi C., Trallori G., Russo A., Palli D., Nutr. Cancer, 42 , $186-190$ (2002).

6) Glinghammar B., Rafter J., Gastroenterology, 120, $401-410$ (2001).

7) Lee Y.-K., Hao W., Ho P.-S., Nordling M., Low C.-S., de Kok T. M. C. M., Rafter J., Nutr Cancer, 52, 35- 42 (2005).

8) Zeng H., Davis C. D., J. Nutr., 133, 2682-2687 (2003).

9) Venturi M., Hambly R. J., Glinghammar B., Rafter J. J., Rowland I. R., Carcinogenesis, 18, 2353-2359 (1997).

10) Glinghammar B., Holmberg K., Rafter J., Carcinogenesis, 20, 969 976 (1999).

11) Haza A. I., Glinghammar B., Grandien A., Rafter J., Nutr. Cancer, 36, 79-89 (2000).

12) Allinger U. G., Johansson G. K., Gustafsson J. A., Rafter J. J., Am. J Clin. Nutr., 50, 992-996 (1989).

13) Karlsson P. C., Huss U., Jenner A., Halliwell B., Bohlin L., Rafter J. J., J. Nutr., 135, 2343-2349 (2005)

14) Lee S. H., Soyoola E., Chanmugam P., Hart S., Sun W., Zhong H., Liou S., Simmons D., Hwang D., J. Biol. Chem., 267, 25934-25938 (1992).

15) Smith W. L., Dewitt D. L.. Adv. Immunol., 62, 167-215 (1996).

16) Weaver S. A., Russo M. P., Wright K. L., Kolios G., Jobin C., Robertson D. A. F., Ward S. G., Gastroenterology, 120, 1117-1127 (2001)

17) Dimberg J., Samuelsson A., Hugander A., Soderkvist P., Gut, 45, $730-732$ (1999)

18) Kargman S. L., O’Neill G. P., Vickers P. J., Evans J. F., Mancini J. A., Jothy S., Cancer Res., 55, 2556-2559 (1995).

19) Subbaramaiah K., Dannenberg A. J., Trends Pharmacol. Sci., 24, 96 102 (2003).

20) Fitzgerald G. A., N. Engl. J. Med., 351, 1709-1711 (2004).

21) Davies N. M., Jamali F., J. Pharm. Pharm. Sci., 7, 332-336 (2004).

22) Eriksson L., Johansson E., Kettaneh-Wold N., Wold S., "Multi- and Megavariate Data Analysis," Umetrics Academy, Umeå (Sweden), 2001, pp. 43-70.

23) Choi Y. H., Sertic S., Kim H. K., Wilson E. G., Michopoulos F., Lefeber A. W. M., Erkelens C., Kricun S. D. P., Verpoorte R., J. Agric Food Chem., 53, 1237-1245 (2005)

24) Choi Y. H., Kim H. K., Linthorst H. J. M., Hollander J. G., Lefeber A. W. M., Erkelens C., Nuzillard J.-M., Verpoorte R., J. Nat. Prod., 69, $742-748$ (2006)

25) Liang Y.-S., Kim H. K., Lefeber A. W. M., Erkelens C., Choi Y. H., Verpoorte R., J. Chromatogr. A, 1112, 148-155 (2006).

26) Lindon J. C., Nicholson J. K., Everett J. R., Ann. Rep. NMR Spectro., 38, 1-88 (1999).

27) Nicholson J. K., Lindon J. C., Holmes E., Xenobiotica, 29, 11811189 (1999).

28) Lindon J. C., Holmes E., Nicholson J. K., Expert Rev. Mol. Diagn., 4, $189-199$ (2004)

29) Marchesi J. R., Holmes E., Khan F., Kochhar S., Scanlan P., Shanahan
F., Wilson I. D., Wang Y., J. Proteome Res., 6, 546-551 (2007).

30) Osswald K., Becker T. W., Grimm M., Jahreis G., Pool-Zobel B. L., Mutat Res., 472, 59-70 (2000).

31) Rieger M. A., Parlesak A., Pool-Zobel B. L., Rechkemmer G., Bode C., Carcinogenesis, 20, 2311-2316 (1999).

32) Glinghammar B., Venturi M., Rowland I. R., Rafter J. J., Am. J. Clin. Nutr, 66, 1277-1282 (1997).

33) Calviello G., Di Nicuolo F., Gragnoli S., Piccioni E., Serini S., Maggiano N., Tringali G., Navarra P., Ranelletti F. O., Palozza P., Carcinogenesis, 25, 2303-2310 (2004).

34) Luceri C., Caderni G., Sanna A., Dolara P., J. Nutr., 132, 1376-1379 (2002).

35) Palozza P., Serini S., Maggiano N., Tringali G., Navarra P., Ranelletti F. O., Calviello G., J. Nutr., 135, 129-136 (2005).

36) Halliwell B., Rafter J., Jenner A., Am. J. Clin. Nutr., 81, 268S-276S (2005).

37) Reddy S., Sanders T. A. B., Owen R. W., Thompson M. H., Br. J. Nutr., 79, 495-500 (1998).

38) Beyer-Sehlmeyer G., Glei M., Hartmann E., Hughes R., Persin C., Böhm V., Rowland I., Schubert R., Jahreis G., Pool-Zobel B. L., Br. J. Nutr., 90, 1057-1070 (2003).

39) Jenner A. M., Rafter J., Halliwell B., Free Radic. Biol. Med., 38 , $763-772(2005)$.

40) Olthof M. R., Hollman C. H., Buijsman M. N. C. P., van Amelsvoort J. M. M., Katan M. B., J. Nutr., 133, 1806-1814 (2003).

41) Aura A. M., Martin-Lopez P., O'Leary K. A., Williamson G., Oksman-Caldentey K.-M., Poutanen K., Santos-Buelga C., Eur. J. Nutr. 44, 133-142 (2005).

42) Jaganath I. B., Mullen W., Edwards C. A., Crozier A., Free Rad. Res., 40, 1035-1046 (2006)

43) Gonthier M.-P., Remesy C., Scalbert A., Cheynier V., Souquet J.-M., Poutanen K., Aura A.-M., Biomed. Pharmacother., 60, 536-540 (2006).

44) Ringbom T., Huss U., Stenholm Å., Flock S., Skattebøl L., Perera P., Bohlin L., J. Nat. Prod., 64, 745-749 (2001).

45) Dommels Y. E. M., Haring M. M. G., Keestra N. G. M., Alink G. M., van Bladeren P. J., van Ommen B., Carcinogenesis, 24, 385-392 (2003).

46) Ringbom T., Segura L., Noreen Y., Perera P., Bohlin L., J. Nat. Prod., 61, 1212-1215 (1998)

47) Llor X., Pons E., Roca A., Alvarez M., Mane J., Fernandez-Banares F., Gassull M. A., Clin. Nutr., 22, 71-79 (2003).

48) Emenaker N. J., Basson M. D., J. Surg. Res., 76, 41-46 (1998).

49) Kiefer J., Beyer-Sehlmeyer G., Pool-Zobel B. L., Br. J. Nutr., 96, $803-810$ (2006)

50) Wong J. M. W., de Souza R., Kendall C. W. C., Emam A., Jenkins D. J. A., J. Clin. Gastroenterol., 40, 235-243 (2006).

51) Tong X., Yin L., Giardina C., Biochem. Biophys. Res. Commun., 317, $463-471$ (2004)

52) Crew T. E., Elder D. J. E., Paraskeva C., Carcinogenesis, 21, 69-77 (2000).

53) Roomi M. W., Ivanov V., Kalinovsky T., Niedzwiecki A., Rath M., Oncol. Rep., 13, 421-425 (2005).

54) Rose M. L., Madren J., Bunzendahl H., Thurman R. G., Carcinogenesis, 20, 793-798 (1999).

55) Wheeler M. D., Ikejema K., Enomoto N., Stacklewitz R. F., Seabra V., Zhong Z., Yin M., Schemmer P., Rose M. L., Rusyn I., Bradford B., Thurman R. G., Cell Mol. Life Sci., 56, 843-856 (1999).

56) Kuroda K., Terao K., Akao M., J. Natl. Cancer Inst., 79, 1047-1051 (1987).

57) Pereira M. A., Barnes L. H., Rassman V. L., Kelloff G. V., Steele V. E., Carcinogenesis, 15, 1049-1054 (1994).

58) Harries M. J., Chalmers R. J., Griffiths C. E., Br. J. Dermatol., 153 $549-551(2005)$

59) Lawrence J. R., Peter R., Baxter G. J., Robson J., Graham A. B., Paterson J. R., J. Clin. Pathol., 56, 651-653 (2003).

60) Teague C., Holmes E., Maibaum E., Nicholson J., Tang H., Chan Q., Elliot P., Wilson I., Analyst, 129, 259-264 (2004).

61) Solanky K. S., Bailey N. J. C., Beckwith-Hall B. M., Davis A., Bingham S., Holmes E., Nicholson J. K., Cassidy A., Anal. Biochem. 323, 197-204 (2003).

62) Mullen W., Boitier A., Stewart A. J., Crozier A., J. Chromatogr. A, 1058, $163-168(2004)$ 